\title{
Clinical Features and Outcome of Surgical Patients with Non-B Non-C Hepatocellular Carcinoma
}

\author{
SHIGEKI WAKIYAMA, MICHINORI MATSUMOTO, KOICHIRO HARUKI, TAKESHI GOCHO, \\ TARO SAKAMOTO, HIROAKI SHIBA, YASURO FUTAGAWA, YUICHI ISHIDA and KATSUHIKO YANAGA \\ Department of Surgery, The Jikei University School of Medicine, Tokyo, Japan
}

\begin{abstract}
Aim: To investigate the clinical characteristics and prognosis of surgical patients with non- $B$ non- $C$ hepatocellular carcinoma (NBNC-HCC) compared to those of hepatitis $B$ virus (HBV)- and hepatitis $C$ virus ( $H C V)$ HCC. Patients and Methods: Clinical data and outcomes were compared among the three groups. Prognostic factors of patients with NBNC-HCC were investigated. Results: Compared to HBV-HCC, patients with NBNC-HCC had higher chance of hypertension $(H T N)(p<0.01)$, diabetes mellitus (DM) and body mass index (BMI) $>25 \mathrm{~kg} / \mathrm{m}^{2}$. Compared to HCV-HCC, patients with NBNC-HCC had higher incidence of DM and higher BMI $>25 \mathrm{~kg} / \mathrm{m}^{2}(p<0.01)$. There were no significant differences in overall survival (OS) rate among the three groups. In patients with $\mathrm{NBNC}-\mathrm{HCC}$, albumin $(A l b ; p<0.05)$ was an independent prognostic factor of $O S$, while Alb and $\alpha$-fetoprotein (AFP) were independent prognostic factors of disease-free survival (DFS; $p<0.01$ each). Conclusion: Surgical patients with NBNC-HCC often have concomitant DM, HTN and high BMI, for whom factors related to prognosis were Alb and AFP.
\end{abstract}

Hepatocellular carcinoma (HCC) is one of the most common malignant tumors in the world. HCC is gradually increasing and, at present, is the sixth most common cancer worldwide, being responsible for approximately 750,000 new cases globally every year (1). In Japan, HCC ranks third in men and fifth in women of cancer deaths (2).

To date, the etiology of HCC development has been reported to include various causative agents, such as hepatitis $\mathrm{B}$ virus (HBV), hepatitis $\mathrm{C}$ virus (HCV), alcohol, primary

Correspondence to: Dr. Shigeki Wakiyama, MD, Ph.D., Department of Surgery, The Jikei University School of Medicine, 3-25-8, Nishishinbashi, Minato-ku, Tokyo, 105-8461, Japan. Tel: +81 334331111, Fax: +81 354724140, e-mail: swakiyama@jikei.ac.jp

Key Words: Non-B Non-C hepatocellular carcinoma, HCV, HBV, outcome, $\alpha$-fetoprotein. biliary cirrhosis, autoimmune hepatitis, hemochromatosis, and Budd-Chiari syndrome (2). Among the various causative agents, the majority of causes of HCC development in Japan have been infection with hepatitis viruses, such as $\mathrm{HCV}$ and $\mathrm{HBV}$, and more than $70-80 \%$ of $\mathrm{HCC}$ are reported to be positive to $\mathrm{HCV}$ antibody, while $10-20 \%$ are positive to hepatitis B surface antigen (3).

In the carcinogenesis of HCV-related HCC, specific gene products of $\mathrm{HCV}$ are reported to be involved in malignant transformation (4), while in that of HBV-related HCC, HBV DNA is integrated into the hepatocyte DNA, resulting in genomic instability, and the gene product $\mathrm{HBx}$ promotes HCC carcinogenesis (5).

Recently, non-B non-C hepatocellular carcinomas (NBNC$\mathrm{HCCs}$ ), which are both $\mathrm{HBs}$ antigen (HBsAg)- and $\mathrm{HCV}$ antibody (HCVAb)-negative, have been gradually increasing in the United States and Japan (2) and suggested to be associated with metabolic syndromes, such as diabetes mellitus (DM) and hypertension (HTN) (6). Actually, with only few reports regarding the characteristics and prognosis in surgical patients with NBNC-HCC, the carcinogenesis and characteristics of the disease remain unclear. It is, therefore, important to clarify carcinogenesis pathway(s), characteristics and prognosis of NBNC-HCC. The aim of the present study was to investigate the clinical characteristics and prognosis of surgical patients with NBNC-HCC as compared with those of HBV- and HCV-related HCC.

\section{Patients and Methods}

Patients. From January 2000 through March 2010, 143 curative hepatic resections for primary HCC were performed at Jikei University Hospital, Tokyo, Japan. Curative hepatic resection was defined as complete macroscopic removal of the tumor with a pathologic negative margin. We could not record survival data of 7 patients who were excluded from the present study. In the preoperative examinations, all patients were tested for the presence of HBsAg and HCVAb; two patients who were positive for both HBsAg and HCVAb were also excluded from this study. Finally, the remaining 134 patients were included and classified into three 
groups according to viral status of hepatitis as follows: HBV group (HBV-HCC, $\mathrm{n}=36,26.9 \%$ ): positive for HBsAg only, $\mathrm{HCV}$ group (HCV-HCC, $\mathrm{n}=57,42.5 \%$ ): positive for HCVAb only and NBNC group (NBNC-HCC, $n=41,30.6 \%$ ): negative for both HBsAg and HCVAb. A total of $134 \mathrm{HCC}$ patients in the present study consisted of $115(85.8 \%)$ men, while the median age was 62 years. The study protocol was approved by the Medical Ethics Committee of the Jikei University and the study was performed in accordance with the ethical standards established in the 1964 Declaration of Helsinki. Written informed consent was obtained in each case.

The preoperative diagnosis of HCC was made by any one or a combination of the following studies: elevated serum tumor markers, such as $\alpha$-fetoprotein (AFP) and protein induced by Vitamin K absence or antagonists-II (PIVKA-II), and findings of ultrasonography, computed tomography (CT), gadoliniumethoxybenzyl-diethylenetriamine pentaacetic acid (Gd-EOB-DTPA)enhanced magnetic resonance imaging (EOB-MRI) or abdominal angiography. Pathological diagnosis was made in all patients based on liver tissue obtained from hepatectomy.

Surgical procedures. The treatment for HCC was generally given according to the consensus-based treatment algorithm for HCC proposed by the Japanese Society of Hepatology (7) and hepatic resection was indicated on the basis of liver function results, the number, size and location of nodules, as well as general condition of patients. The surgical procedure for HCC was generally selected in accordance with "Indications for hepatectomy " advocated by Makuuchi et al. (8) and surgical procedures, such as anatomical and limited resection, were classified according to the Brisbane terminology proposed by Strasberg et al. (9).

Follow-up of surgical patients after hepatectomy for HCC. All surgical patients were followed up at least every 3 months after hepatectomy. Postoperative evaluation included physical examinations, liver function and tumor marker tests, as well as ultrasonography, CT or EOB-MRI to check for intrahepatic recurrence. Chest $\mathrm{CT}$ was performed once a year and bone scintigraphy was performed if necessary. When intrahepatic recurrence was detected during the follow-up evaluations, treatment for recurrence, such as repeat resection, ablation and transarterial chemoembolization (TACE), was selected according to remnant hepatic functional reserve, the number, size and location of hepatic recurrence, as well as patients' general condition. For extrahepatic recurrence, molecular-targeted therapy was introduced after 2009.

Annual trend in virus status in surgical patients with HCC. Annual trend in virus status was studied to examine the incidence of surgical patients with NBNC-HCC.

Comparisons of the clinical variables in surgical patients between $N B N C$ - and $H B V-H C C$ or $H C V-H C C$. The following clinical variables in surgical patients were compared to investigate the differences between NBNC-HCC and HBV- or HCV-HCC, respectively; age, gender, body mass index (BMI) $>25 \mathrm{~kg} / \mathrm{m}^{2}$, presence or absence of DM and HTN, alcohol intake $>20$ gram per day, serum aspartate aminotransferase (AST), alanine aminotransferase (ALT), total bilirubin (T-bil), albumin (Alb), alkaline phosphatase (Al-P) or $\gamma$-glutamyl transpeptidase ( $\gamma$-GTP), peripheral white blood cell (WBC) count or platelet (Plt) count, Creactive protein (CRP), indocyanine green retention test at $15 \mathrm{~min}$

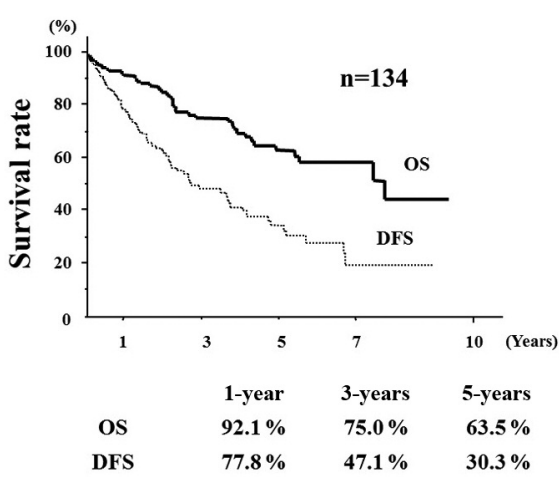

Figure 1. Overall survival (OS) and disease-free survival (DFS) of all surgical patients with hepatocellular carcinoma (HCC) (January 2000March 2010, n=134). The 3- and 5-year cumulative overall survival rates were $75.0 \%$ and $63.5 \%$, respectively, while the 3 - and 5-year cumulative disease-free survival rates were $47.1 \%$ and $30.3 \%$, respectively.

(ICGR15), maximal tumor diameter (max TD), number of tumors (solitary or multiple), TNM stage, the serum tumor markers AFP and PIVKA-II at the time of diagnosis for HCC, operative time, intraoperative blood loss and the perioperative use of blood products, such as red cell concentrates (RCCs) and fresh frozen plasma (FFP). DM and HTN were diagnosed when patients were pharmacologically treated for those diseases or on the basis of medical records.

Survival and prognostic factor analyses in surgical patients with $N B N C$-HCC. Overall survival (OS) and disease-free survival (DFS) rates of the three groups after curative resection were compared using the Kaplan-Meier method and the log-rank test. In NBNC$\mathrm{HCC}$, factors related to OS and DFS were investigated using univariate and multivariate analyses.

Statistical analyses. All data are expressed as means \pm standard deviation (SD). Comparison of categorical variables were conducted using either the $\chi^{2}$ test or the Fisher's exact test, as appropriate, and continuous variables were compared by the Mann-Whitney's $U$-test. The survival curves were analyzed by the Kaplan-Meier method and compared with the log-rank test. A Cox proportional hazards model was used for uni- and multivariate analyses for factors that influenced OS and DFS. In uni- and multivariate analyses, continuous variables were used to divide patients into 2 groups based on the median values. Only those variables showing a value of $p<0.10$ in univariate analyses were included in the overall multivariate Cox model. StatView for Windows software (version 5.0; SAS Institute Inc., Cary, NC, USA) was used for analyses in the present study. All $p$-values $<0.05$ were considered statistically significant.

\section{Results}

Patients. Figure 1 shows OS and DFS rates of 134 patients with HCC, with their backgrounds being summarized in Table I. 
Table I. Clinical characteristics of all surgical patients with HCC.

\begin{tabular}{|c|c|}
\hline Variable & All patients $(n=134)$ \\
\hline Age (years) & $62 \pm 11 *$ \\
\hline Gender (male:female) & $115: 19$ \\
\hline \multicolumn{2}{|l|}{ Virus type } \\
\hline HBV-HCC & 36 \\
\hline $\mathrm{HCV}-\mathrm{HCC}$ & 57 \\
\hline NBNC-HCC & 41 \\
\hline DM (yes) & $30(22.4 \%)$ \\
\hline HTN (yes) & $50(37.3 \%)$ \\
\hline BMI $\left(\mathrm{kg} / \mathrm{m}^{2}\right)$ & $23.6 \pm 3.2$ \\
\hline Alcohol intake $>20 \mathrm{~g} /$ day & $54(40.3 \%)$ \\
\hline Serum AST (IU/l) & $45 \pm 28$ \\
\hline Serum ALT (IU/1) & $47 \pm 36$ \\
\hline Serum total bilirubin $(\mathrm{mg} / \mathrm{dl})$ & $0.9 \pm 0.4$ \\
\hline Serum albumin $(\mathrm{g} / \mathrm{dl})$ & $3.9 \pm 0.5$ \\
\hline Serum Al-P (IU/l) & $302 \pm 138$ \\
\hline Serum $\gamma$-GTP (IU/l) & $47 \pm 36$ \\
\hline White blood cell $(/ \mu \mathrm{l})$ & $5,061 \pm 1,856$ \\
\hline Platelet $\left(\times 10^{3} / \mu \mathrm{l}\right)$ & $151 \pm 62$ \\
\hline Serum CRP (mg/dl) & $0.33 \pm 0.97$ \\
\hline ICG R15 (\%) & $14.4 \pm 8.8$ \\
\hline Serum AFP (ng/ml) & $6,475 \pm 42,055$ \\
\hline Serum PIVKA-II (mAU/ml) & $1,079.3 \pm 3,446.5$ \\
\hline $\operatorname{Max} \mathrm{TD}(\mathrm{cm})$ & $4.5 \pm 3.4$ \\
\hline Number of tumors (solitary/multiple) & $107 / 27$ \\
\hline Stage $(\mathrm{I}+\mathrm{II} / \mathrm{III}+\mathrm{IV})$ & $121 / 13$ \\
\hline Operative time (min) & $364.1 \pm 156.0$ \\
\hline Intraoperative blood loss (ml) & $1,533 \pm 2,811$ \\
\hline \multicolumn{2}{|l|}{ Intraoperative use of blood products } \\
\hline RCC (yes/no) & $40 / 94$ \\
\hline FFP (yes/no) & $44 / 90$ \\
\hline
\end{tabular}

*means \pm SD; NBNC-HCC, Non-B non-C- hepatocellular carcinoma; $\mathrm{HBV}$, hepatitis B virus; $\mathrm{HCV}$, hepatitis $\mathrm{C}$ virus; $\mathrm{AFP}, \alpha$-fetoprotein; ALT, alanine aminotransferase; AST, aspartate aminotransferase; ICGR 15, indocyanine green retention test at $15 \mathrm{~min} ; \gamma$-GTP, $\gamma$-glutamyl transpeptidase; PIVKA-II, protein induced by Vitamin $\mathrm{K}$ absence or antagonists-II; CRP, C-reactive protein; Al-P, alkaline phosphatase; DM, diabetes mellitus; HTN, hypertension; Max TD, maximal tumor diameter; RCC, red cell concentrates; FFP, fresh-frozen plasma.

Annual number of NBNC-HCC in surgical patients with $H C C$. Figure 2 depicts the annual distribution of NBNC$\mathrm{HCC}$ in all surgical patients with HCC.

Comparison of clinical characteristics between NBNC-and $H B V-H C C$. As shown in Table II, patients with NBNC-HCC as compared with HBV-HCC had a significantly higher incidence of HTN $(p<0.01)$, while DM and BMI $>25 \mathrm{~kg} / \mathrm{m}^{2}$ were more frequent. Patients with NBNC-HCC were significantly older and their max TD was larger than those in HBV-HCC $(p<0.05)$, respectively. Patients with NBNC-HCC had significantly more intraoperative blood loss $(p<0.05)$ and more blood transfusion of RCC $(p<0.01)$ than those with HBV-HCC.

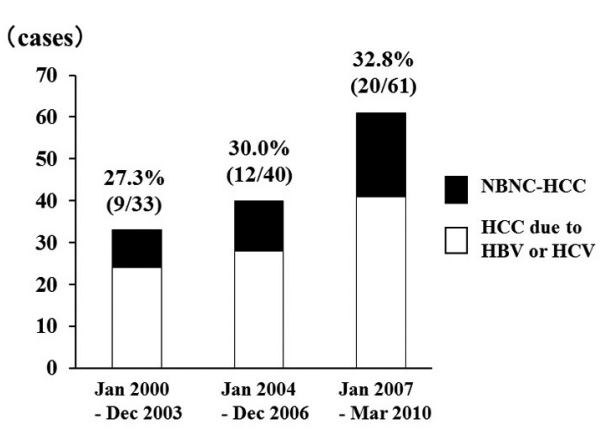

Figure 2. The incidence of non-B non-C hepatocellular carcinoma $(N B N C-H C C)$ in relation to overall surgical patients with hepatocellular carcinoma (HCC) (January 2000-March 2010, $n=134$ ). NBNC-HCC accounted for $27.3 \%$ between January 2000 to December 2003, 30.0\% between January 2004 to December 2006 and 32.8\% between January 2007 to March 2010.

Comparison of clinical characteristics between NBNC-and $H C V-H C C$. As shown in Table III, patients with NBNC-HCC as compared with $\mathrm{HCV}-\mathrm{HCC}$ had a significantly higher incidence of $\mathrm{BMI}>25 \mathrm{~kg} / \mathrm{m}^{2}(p<0.01)$, while DM was more frequent. Also, the values of serum AST, ALT, $\gamma$-GTP and ICG R15 were significantly lower $(p<0.01)$, respectively. Both peripheral white blood cell and platelet counts were significantly higher $(p<0.01)$, respectively. Maximal TD and the value of serum AFP were also significantly increased $(p<0.01)$, respectively. Operative time in patients with NBNC-HCC was significantly longer than that with HCVHCC $(p<0.05)$. Patients with NBNC-HCC had significantly more intraoperative blood loss $(p<0.05)$ and more blood transfusion of RCC $(p<0.01)$ and FFP $(p<0.05)$ than those with HCV-HCC.

Survival and prognostic factor analyses in surgical patients with NBNC-HCC. Figures 3 and 4 show OS and DFS rates of 134 patients with HCC in relation to viral type. There were no significant differences in OS rate among the three groups, while NBNC-HCC tended to have a better DFS, which, however, did not achieve statistical significance.

Tables IV and $\mathrm{V}$ show the relationship between the clinical variables and OS or DFS in NBNC-HCC. In univariate analysis, as shown in Table IV, OS rate was significantly worse in patients with lower serum Alb $(p<0.01)$, whereas DM tended to be associated with worse OS $(p=0.076)$. In multivariate analysis of OS shown in Table $\mathrm{V}$, serum Alb $(p<0.05)$ was an independent prognostic factor of OS. On the other hand, in univariate analysis as shown in Table IV, DFS was significantly worse in older patients $(p<0.05)$, while patients showed higher serum AST $(p<0.05)$, lower serum Alb $(p<0.01)$ and higher value of serum AFP 
Table II. Comparison of clinical variables between NBNC- and HBVHCC.

\begin{tabular}{|c|c|c|c|}
\hline Variable & $\begin{array}{c}\text { NBNC-HCC } \\
(\mathrm{n}=41)\end{array}$ & $\begin{array}{l}\mathrm{HBV}-\mathrm{HCC} \\
\quad(\mathrm{n}=36)\end{array}$ & $p$-Value \\
\hline Age (years) & $63 \pm 12 *$ & $52 \pm 9$ & $<0.0001$ \\
\hline Gender (male:female) & $36: 5$ & $33: 3$ & 0.579 \\
\hline $\mathrm{BMI}>25 \mathrm{~kg} / \mathrm{m}^{2}$ & $48.8 \%$ & $31.4 \%$ & 0.103 \\
\hline DM & $34.1 \%$ & $16.7 \%$ & 0.080 \\
\hline HTN & $51.2 \%$ & $14.3 \%$ & 0.0005 \\
\hline Alcohol intake $>20 \mathrm{~g} /$ day & $43.9 \%$ & $30.6 \%$ & 0.306 \\
\hline Serum AST (IU/l) & $38 \pm 25$ & $39 \pm 14$ & 0.052 \\
\hline Serum ALT (IU/1) & $36 \pm 22$ & $42 \pm 19$ & 0.045 \\
\hline Serum total bilirubin $(\mathrm{mg} / \mathrm{dl})$ & $0.9 \pm 0.4$ & $1.0 \pm 0.5$ & 0.274 \\
\hline Serum albumin $(\mathrm{g} / \mathrm{dl})$ & $3.9 \pm 0.5$ & $4.0 \pm 0.4$ & 0.660 \\
\hline Serum Al-P (IU/l) & $316 \pm 153$ & $323 \pm 185$ & 0.831 \\
\hline Serum $\gamma$-GTP (IU/1) & $36 \pm 22$ & $42 \pm 19$ & 0.045 \\
\hline White blood cell $(/ \mu \mathrm{l})$ & $5,635 \pm 1,845$ & $5,239 \pm 1,929$ & 0.365 \\
\hline Platelet $\left(\times 10^{3} / \mu \mathrm{l}\right)$ & $177 \pm 70$ & $151 \pm 55$ & 0.059 \\
\hline Serum CRP & $0.62 \pm 1.60$ & $0.57 \pm 1.74$ & 0.063 \\
\hline ICG R15 (\%) & $11.5 \pm 6.9$ & $11.7 \pm 5.8$ & 0.669 \\
\hline Serum AFP (ng/ml) & $8,741 \pm 46,243$ & $11,499 \pm 64,148$ & 80.151 \\
\hline Serum PIVKA-II (mAU/ml) & $2,249 \pm 5,546$ & $861 \pm 2,179$ & 0.285 \\
\hline $\operatorname{Max} \mathrm{TD}(\mathrm{cm})$ & $6.3 \pm 4.2$ & $4.4 \pm 3.5$ & 0.0175 \\
\hline \multicolumn{4}{|l|}{ Number of tumors } \\
\hline (solitary/multiple) & $34 / 7$ & $27 / 9$ & 0.392 \\
\hline TNM stage (I+II/III+IV) & $35 / 6$ & $32 / 4$ & 0.646 \\
\hline Operation time (min) & $413.0 \pm 174.8$ & $353.7 \pm 162.4$ & 0.133 \\
\hline Intraoperative blood loss (ml) & $2,254 \pm 4,067$ & $1,465 \pm 2,886$ & 0.044 \\
\hline \multicolumn{4}{|l|}{$\begin{array}{l}\text { Intraoperative use of } \\
\text { blood products }\end{array}$} \\
\hline RCC (yes/no) & $21 / 20$ & $7 / 29$ & 0.003 \\
\hline FFP (yes/no) & $19 / 22$ & $12 / 24$ & 0.245 \\
\hline
\end{tabular}

*means \pm SD; DM, Diabetes mellitus; HTN, hypertension; Max TD, maximal tumor diameter; RCC, red cell concentrates; FFP, fresh-frozen plasma; NBNC-HCC, non-B non-C- hepatocellular carcinoma; HBV, hepatitis B virus; AFP, $\alpha$-fetoprotein; ALT, alanine aminotransferase; AST, aspartate aminotransferase; ICGR 15, indocyanine green retention test at $15 \mathrm{~min} ; \gamma$-GTP, $\gamma$-glutamyl transpeptidase; PIVKA-II, protein induced by Vitamin $\mathrm{K}$ absence or antagonists-II; CRP, C-reactive protein; Al-P, alkaline phosphatase.

$(p<0.05)$. In multivariate analysis, as shown in Table V, serum Alb $(p<0.01)$ and AFP $(p<0.01)$ were independent prognostic factors of DFS.

\section{Discussion}

In the present study, we found that the incidence of surgical patients with NBNC-HCC is gradually increasing. The study's findings are in agreement with previous reports demonstrating an increased number and rate of patients with NBNC-HCC accounting for $20 \%$ of all HCC patients (2). Therefore, it was important to clarify the characteristics of surgical patients with NBNC-HCC for optimal pre- and post-operative management.
Table III. Comparison of clinical variables between NBNC- and HCVHCC.

\begin{tabular}{|c|c|c|c|}
\hline Variable & $\begin{array}{c}\text { NBNC-HCC } \\
(n=41)\end{array}$ & $\begin{array}{l}\mathrm{HCV}-\mathrm{HCC} \\
\quad(\mathrm{n}=57)\end{array}$ & $p$-Value \\
\hline Age (years) & $63 \pm 12 *$ & $67 \pm 7$ & 0.403 \\
\hline Gender (male:female) & $36: 5$ & $46: 11$ & 0.348 \\
\hline $\mathrm{BMI}>25 \mathrm{~kg} / \mathrm{m}^{2}$ & $48.8 \%$ & $19.3 \%$ & 0.002 \\
\hline $\mathrm{DM}$ & $34.1 \%$ & $17.5 \%$ & 0.059 \\
\hline HTN & $51.2 \%$ & $42.1 \%$ & 0.371 \\
\hline Alcohol intake $>20 \mathrm{~g} /$ day & $43.9 \%$ & $28.1 \%$ & 0.118 \\
\hline Serum AST (IU/l) & $38 \pm 25$ & $52 \pm 34$ & 0.0006 \\
\hline Serum ALT (IU/l) & $36 \pm 22$ & $58 \pm 47$ & 0.0028 \\
\hline Serum total bilirubin $(\mathrm{mg} / \mathrm{dl})$ & $0.9 \pm 0.4$ & $0.9 \pm 0.3$ & 0.405 \\
\hline Serum albumin (g/dl) & $3.9 \pm 0.5$ & $3.8 \pm 0.4$ & 0.068 \\
\hline Serum Al-P (IU/l) & $316 \pm 153$ & $279 \pm 82$ & 0.296 \\
\hline Serum $\gamma$-GTP (IU/l) & $36 \pm 22$ & $58 \pm 47$ & 0.0028 \\
\hline White blood cell $(/ \mu \mathrm{l})$ & $5,635 \pm 1,845$ & $4,546 \pm 1,702$ & 0.0003 \\
\hline Platelet $\left(\times 10^{3} / \mu \mathrm{l}\right)$ & $177 \pm 70$ & $132 \pm 53$ & 0.0003 \\
\hline Serum CRP & $0.62 \pm 1.60$ & $0.27 \pm 0.53$ & 0.326 \\
\hline ICG R15 (\%) & $11.5 \pm 6.9$ & $18.1 \pm 10.1$ & 0.0002 \\
\hline Serum AFP (ng/ml) & $8,741 \pm 46,243$ & $1,583 \pm 4,493$ & 0.0091 \\
\hline Serum PIVKA-II (mAU/ml) & $2,249 \pm 5,546$ & $289 \pm 556$ & 0.096 \\
\hline $\operatorname{Max} T D(\mathrm{~cm})$ & $6.3 \pm 4.2$ & $3.3 \pm 1.7$ & $<0.0001$ \\
\hline \multicolumn{4}{|l|}{ Number of tumors } \\
\hline (solitary/multiple) & $34 / 7$ & $46 / 11$ & 0.779 \\
\hline Stage (I+II/III+IV) & $35 / 6$ & $54 / 3$ & 0.113 \\
\hline Operation time (min) & $413.0 \pm 174.8$ & $335.3 \pm 129.8$ & 0.036 \\
\hline Intraoperative blood loss & $2,254 \pm 4,067$ & $1,056 \pm 1,063$ & 0.048 \\
\hline \multicolumn{4}{|l|}{$\begin{array}{l}\text { Intraoperative use of } \\
\text { blood products }\end{array}$} \\
\hline RCC (yes/no) & $21 / 20$ & $12 / 45$ & 0.0018 \\
\hline FFP (yes/no) & $19 / 22$ & $13 / 44$ & 0.014 \\
\hline
\end{tabular}

*means \pm SD; DM, Diabetes mellitus; HTN, hypertension; Max TD, maximal tumor diameter; RCC, red cell concentrates; FFP, fresh-frozen plasma; NBNC-HCC, non-B non-C- hepatocellular carcinoma; HCV, hepatitis $\mathrm{C}$ virus; AFP, $\alpha$-fetoprotein; ALT, alanine aminotransferase; AST, aspartate aminotransferase; ICGR15, indocyanine green retention test at $15 \mathrm{~min} ; \gamma$-GTP, $\gamma$-glutamyl transpeptidase; PIVKA-II, protein induced by Vitamin $\mathrm{K}$ absence or antagonists-II; CRP, C-reactive protein; Al-P, alkaline phosphatase.
It is suggested that NBNC-HCC might be associated with obesity, DM and metabolic syndromes, which are at an increased risk for developing HCC (6).

The current study demonstrated the clinical characteristics of surgical patients with NBNC-HCC in comparison to those of surgical patients with $\mathrm{HBV}-\mathrm{HCC}$ or $\mathrm{HCV}-\mathrm{HCC}$; the results were consistent with previous reports (10). We, herein, showed that NBNC-HCC and HBV-HCC patients seem to share similar factors in their background characteristics. Shiraishi et al. (11) have reported that HBV-DNA is found frequently in the noncancerous region of liver tissue in NBNC-HCC patients, while Hatanaka et al. (10) also speculated the possible association of $\mathrm{HBV}$ with hepatocarcinogenesis to some extent in NBNC-HCC 
Table IV. Univariate analysis of the prognostic factors for OS and DFS in NBNC-HCC.

\begin{tabular}{|c|c|c|c|c|}
\hline \multirow[b]{2}{*}{ Variables } & \multicolumn{2}{|c|}{ OS (years) } & \multicolumn{2}{|c|}{ DFS (years) } \\
\hline & median & $p$-Value & median & $p$-Value \\
\hline Age (years) & & 0.596 & & 0.040 \\
\hline$\geq 66(n=21)$ & 0.879 & & 0.778 & \\
\hline$<66(\mathrm{n}=20)$ & 3.323 & & 3.097 & \\
\hline Gender & & 0.933 & & 0.821 \\
\hline male $(n=36)$ & 2.492 & & 1.564 & \\
\hline female $(n=5)$ & 0.778 & & 0.573 & \\
\hline BMI $\left(\mathrm{kg} / \mathrm{m}^{2}\right)$ & & 0.165 & & 0.896 \\
\hline$\geq 24.9(\mathrm{n}=21)$ & 1.367 & & 1.170 & \\
\hline$<24.9(\mathrm{n}=20)$ & 2.886 & & 1.347 & \\
\hline DM & & 0.076 & & 0.345 \\
\hline yes $(n=14)$ & 1.375 & & 1.042 & \\
\hline no $(n=27)$ & 3.162 & & 1.386 & \\
\hline HTN & & 0.552 & & 0.533 \\
\hline yes $(n=21)$ & 3.162 & & 1.386 & \\
\hline no $(n=20)$ & 0.877 & & 0.867 & \\
\hline Serum AST (IU/l) & & 0.174 & & 0.031 \\
\hline$\geq 1 \quad(n=21)$ & 1.123 & & 0.888 & \\
\hline$<31(\mathrm{n}=19)$ & 3.162 & & 2.611 & \\
\hline Serum ALT (IU/l) & & 0.734 & & 0.659 \\
\hline$\geq 29(\mathrm{n}=21)$ & 2.092 & & 1.870 & \\
\hline$<29(\mathrm{n}=19)$ & 1.384 & & 0.874 & \\
\hline Serum total bilirubin $(\mathrm{mg} / \mathrm{dl})$ & & 0.652 & & 0.782 \\
\hline$\geq 0.8(n=25)$ & 2.611 & & 1.386 & \\
\hline$<0.8(\mathrm{n}=16)$ & 1.096 & & 1.090 & \\
\hline Serum albumin $(\mathrm{g} / \mathrm{dl})$ & & 0.001 & & $<$ \\
\hline 0.0001 & & & & \\
\hline$\geq 4.0(n=22)$ & 3.048 & & 2.492 & \\
\hline$<4.0(\mathrm{n}=19)$ & 1.307 & & 0.915 & \\
\hline Serum Al-P (IU/l) & & 0.436 & & 0.121 \\
\hline$\geq 291.5(n=21)$ & 1.307 & & 1.170 & \\
\hline$<291.5(\mathrm{n}=20)$ & 2.886 & & 2.492 & \\
\hline Serum $\gamma$-GTP (IU/l) & & 0.734 & & 0.659 \\
\hline$\geq 29(\mathrm{n}=21)$ & 2.092 & & 1.870 & \\
\hline$<29(\mathrm{n}=19)$ & 1.384 & & 0.874 & \\
\hline White blood cell $(/ \mu \mathrm{l})$ & & 0.720 & & 0.962 \\
\hline$\geq 5,400(\mathrm{n}=21)$ & 1.384 & & 1.170 & \\
\hline$<5,400(\mathrm{n}=19)$ & 2.886 & & 1.377 & \\
\hline Platelet $\left(\times 10^{3} / \mu \mathrm{l}\right)$ & & 0.435 & & 0.681 \\
\hline$\geq 171(n=21)$ & 1.384 & & 1.307 & \\
\hline$<171(\mathrm{n}=20)$ & 2.211 & & 1.268 & \\
\hline Serum CRP (mg/dl) & & 0.173 & & 0.066 \\
\hline$\geq 0.10(\mathrm{n}=21)$ & 1.811 & & 1.170 & \\
\hline$<0.10(\mathrm{n}=18)$ & 1.870 & & 1.870 & \\
\hline
\end{tabular}

patients. Therefore, carcinogenesis of NBNC-HCC might be associated with HBV carcinogenesis.

The relationship between OS or DFS and viral status has been controversial. Kondo et al. (12) have showed that OS and DFS rates in NBNC-HCC patients are significantly better than those in HBV- and HCV-HCC patients, respectively. Also, several other reports $(13,14)$ have shown that OS rate in NBNC- or non-alcoholic fatty liver disease

\begin{tabular}{|c|c|c|c|c|}
\hline \multirow[b]{2}{*}{ Variables } & \multicolumn{2}{|c|}{ OS (years) } & \multicolumn{2}{|c|}{ DFS (years) } \\
\hline & median & $p$-Value & median & $p$-Value \\
\hline ICG R15 (\%) & & 0.711 & & 0.879 \\
\hline$\geq 10(n=23)$ & 1.384 & & 1.170 & \\
\hline$<10(\mathrm{n}=18)$ & 2.492 & & 1.347 & \\
\hline Serum AFP (ng/ml) & & 0.286 & & 0.021 \\
\hline$\geq 20(n=13)$ & 1.134 & & 0.645 & \\
\hline$<20(\mathrm{n}=26)$ & 2.611 & & 1.742 & \\
\hline Serum PIVKA-II (mAU/ml) & & 0.243 & & 0.377 \\
\hline$\geq 400(n=16)$ & 1.997 & & 1.555 & \\
\hline$<400(n=21)$ & 1.811 & & 1.170 & \\
\hline $\operatorname{Max}$ TD $(\mathrm{cm})$ & & 0.614 & & 0.701 \\
\hline$\geq 4.5(\mathrm{n}=23)$ & 0.885 & & 0.860 & \\
\hline$<4.5(\mathrm{n}=18)$ & 3.942 & & 2.097 & \\
\hline Number of tumors & & 0.088 & & 0.111 \\
\hline solitary $(n=34)$ & 2.886 & & 2.058 & \\
\hline multiple $(n=7)$ & 0.874 & & 0.860 & \\
\hline TNM stage & & 0.263 & & 0.453 \\
\hline $\mathrm{I}+\mathrm{II}(\mathrm{n}=35)$ & 2.611 & & 1.386 & \\
\hline $\mathrm{III}+\mathrm{IV}(\mathrm{n}=6)$ & 0.873 & & 0.645 & \\
\hline Operative time (min) & & 0.623 & & 0.075 \\
\hline$\geq 410(\mathrm{n}=21)$ & 1.307 & & 0.778 & \\
\hline$<410(n=20)$ & 3.489 & & 2.452 & \\
\hline Intraoperative blood loss (ml) & & 0.775 & & 0.404 \\
\hline$\geq 1,280(\mathrm{n}=21)$ & 3.162 & & 1.386 & \\
\hline$<1,280(\mathrm{n}=20)$ & 1.375 & & 1.042 & \\
\hline Intraoperative use of RCC & & 0.444 & & 0.058 \\
\hline yes $(n=21)$ & 2.611 & & 1.307 & \\
\hline no $(n=20)$ & 1.597 & & 1.268 & \\
\hline Intraoperative use of FFP & & 0.342 & & 0.922 \\
\hline yes $(n=19)$ & 1.367 & & 1.307 & \\
\hline no $(n=22)$ & 2.092 & & 1.456 & \\
\hline
\end{tabular}

*means \pm SD; OS, Overall survival; DFS, disease-free survival; NBNC$\mathrm{HCC}$, non-B non-C- hepatocellular carcinoma; HBV, hepatitis B virus; $\mathrm{HCV}$, hepatitis $\mathrm{C}$ virus; AFP, $\alpha$-fetoprotein; ALT, alanine aminotransferase; AST, aspartate aminotransferase; ICGR15, indocyanine green retention test at $15 \mathrm{~min} ; \gamma$-GTP, $\gamma$-glutamyl transpeptidase; PIVKA-II, protein induced by Vitamin K absence or antagonists-II; CRP, C-reactive protein; Al-P, alkaline phosphatase; DM, diabetes mellitus; HTN, hypertension; Max TD, maximal tumor diameter; RCC, red cell concentrates; FFP, fresh-frozen plasma; TNM, tumor-node-metastasis.
(NAFLD)-HCC patients are significantly better than that in HCV-HCC patients. On the other hand, some reports $(15,16)$ have shown no difference in OS in relation to viral status. Kaibori et al. (17) have found significant differences in DFS rate, but not in OS rate among the three groups, and demonstrated that both OS and DFS of patients with NBNCHCC after hepatic resection are significantly better in cases with a maximal tumor diameter of $5 \mathrm{~cm}$ or less. Subgroup 


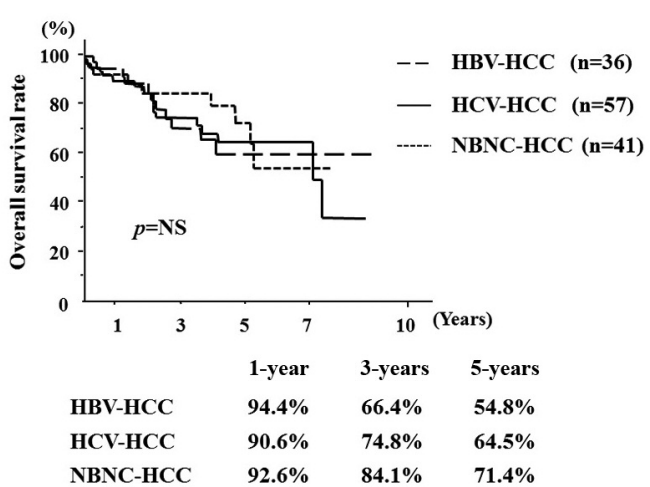

Figure 3. Overall survival (OS) of 134 patients with hepatocellular carcinoma (HCC) at our Institute in relation to status of viral hepatitis: hepatitis $B$ virus $(H B V)$, hepatitis $C$ virus $(H C V)$ and non- $B$ non-C hepatocellular carcinoma (NBNC). There were no significant differences in OS rate among the three groups. NS, Not significant.

analysis of patients with NBNC-HCC will be needed as the NBNC-HCC group is composed of patients affected by various etiologies, including non-alcoholic steatohepatitis (NASH), NAFLD, alcohol abuse and others, still unknown.

In the present study, we demonstrated that serum Alb is a prognostic factor for OS and serum Alb and AFP for DFS using uni- and multivariate analyses. Until now, reported prognostic factors in patients with NBNC-HCC after hepatic resection include tumor diameter, multiple tumors, portal invasion and curative resection with an adequate surgical margin $(13,18)$, which, however, remain controversial.

Kaibori et al. (17) reported serum Alb and PIVKA-II levels to be independent predictors of OS and DFS in patients with NBNC-HCC after hepatectomy. On the other hand, some authors report that AFP could be an independent prognostic factor in patients with NBNC-HCC or NAFLD. Wakai et al. (15) have demonstrated that serum AFP could be an independent prognostic factor after hepatectomy in patients with HCC in NAFLD, whereas Babali et al. (19) have shown that AFP levels could rise in accordance with the grade of liver steatosis in NAFLD. Also, Witjes et al. (20) have reported significant association between increased serum AFP levels and clinical outcome of non-cirrhotic patients with HCC without well-established risk factors, such as hepatitis $\mathrm{B}$ or $\mathrm{C}$ infection, alcohol abuse and hemochromatosis. Therefore, we believe that serum AFP level could be an independent prognostic factor of DFS in NBNC-HCC patients.

We also demonstrated that serum Alb level is an independent prognostic factor for OS and DFS and we, therefore, suggest that nutritional therapy might be beneficial

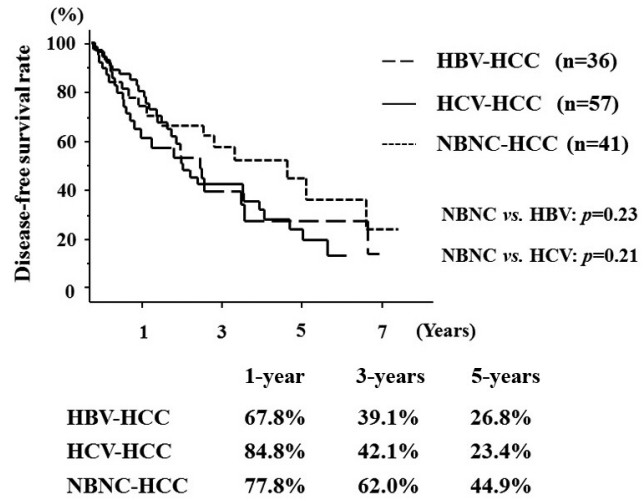

Figure 4. Disease-free survival (DFS) of 134 patients with hepatocellular carcinoma $(H C C)$ at our Institute in relation to status of viral hepatitis: hepatitis $B$ virus ( $H B V)$, hepatitis $C$ virus $(H C V)$ and non- $B$ non- $C$ hepatocellular carcinoma (NBNC). There was a tendency for better DFS rate in patients with NBNC-HCC as compared to those with the other groups, which did not, however, achieve statistical significance.

Table V. Multivariate analyses of the prognostic factors for OS and DFS in $\mathrm{NBNC}-\mathrm{HCC}$.

\begin{tabular}{lcc}
\hline OS or DFS & $p$-Value & Relative risk \\
\hline OS & & \\
DM (yes) & 0.360 & 2.048 \\
Serum albumin $<4.0 \mathrm{~g} / \mathrm{dl}$ & 0.021 & 12.642 \\
Number of tumors (multiple) & 0.275 & 2.616 \\
DFS & & \\
Age $\geq 66$ years & 0.109 & 3.389 \\
Serum AST $\geq 31 \mathrm{IU} / 1$ & 0.860 & 1.160 \\
Serum albumin $<4.0 \mathrm{~g} / \mathrm{dl}$ & 0.0002 & 152.558 \\
Serum CRP $\geq 0.10 \mathrm{mg} / \mathrm{dl}$ & 0.165 & 4.198 \\
Serum AFP $\geq 20 \mathrm{ng} / \mathrm{ml}$ & 0.0072 & 9.121 \\
Operative time $\geq 410 \mathrm{~min}$ & 0.137 & 4.275 \\
Intraoperative use of RCC (yes) & 0.478 & 0.507 \\
\hline
\end{tabular}

OS, Overall survival; DFS, disease-free survival; NBNC-HCC, non-B non-C- hepatocellular carcinoma; HBV, hepatitis B virus; HCV, hepatitis $\mathrm{C}$ virus; AFP, $\alpha$-fetoprotein; AST, aspartate aminotransferase; CRP, C-reactive protein; DM, diabetes mellitus; RCC, red cell concentrates.

to improve OS in patients with NBNC-HCC. Further prospective studies are required to validate the significance of serum Alb and AFP as prognostic factor of NBNC-HCC.

There are several limitations associated with the present study. First, this single-center study's design was retrospective and, therefore, there may be potential selection bias for the patients with HCC after hepatectomy. Second, pathological findings from all three groups were not 
available. Finally, we were unable to properly evaluate the subgroup of patients with NBNC-HCC and, therefore, analysis of subgroup of patients with NBNC-HCC would be needed in the future, although it would be complicated to divide NBNC-HCC group into subgroups according to the etiology of NBNC-HCC, such as occult HBV, NAFLD, NASH, alcohol abuse and unknown $(21,22)$.

In conclusion, surgical patients with NBNC-HCC have been gradually increasing. The present study elucidated that surgical patients with NBNC-HCC have a high incidence of DM, HTN and BMI $>25 \mathrm{~kg} / \mathrm{m}^{2}$ and clinical factors related to prognosis seem to be serum Alb and AFP.

\section{Conflicts of Interest}

All Authors disclose no conflicts.

\section{References}

1 Ferlay J, Shin HR, Bray F, Forman D, Mathers C and Parkin DM: Estimates of worldwide burden of cancer in 2008: GLOBOCAN 2008. Int J Cancer 127: 2893-917, 2010.

2 Nagaoki $Y$, Hyogo H, Aikata H, Tanaka M, Naeshiro N, Nakahara T, Honda Y, Miyaki D, Kawaoka T, Takaki S, Hiramatsu A, Waki K, Imamura M, Kawakami Y, Takahashi S and Chayama K: Recent trend of clinical features in patients with hepatocellular carcinoma. Hepatol Res 42: 368-375, 2012.

3 Ikai I, Kudo M, Arii S, Omata M, Kojiro M, Sakamoto M, Takayasu k, Hayashi N, Makuuchi M, Matsuyama Y and Monden M: Report of the 18th follow-up survey of primary liver cancer in Japan. Hepatol Res 40: 1043-1059, 2010.

4 Dohmen K, Shigematsu H, Irie K and Ishibashi H: Comparison of the clinical characteristics among hepatocellular carcinoma of hepatitis $\mathrm{B}$, hepatitis $\mathrm{C}$ and non- $\mathrm{B}$ non-C patients. Hepatogastroenterology 50: 2022-2027, 2003.

5 Arzumanyan A, Reis HM and Feitelson MA: Pathogenic mechanisms in HBV- and HCV-associated hepatocellular carcinoma. Nat Rev Cancer 13: 123-135, 2013.

6 Siegel AB and Zhu AX: Metabolic syndrome and hepatocellular carcinoma: Two growing epidemics with a potential link. Cancer 115: 5651-5661, 2009.

7 Kudo M, Matsui O, Izumi N, Iijima H, Kadoya M, Imai Y, Okusaka T, Miyayama S, Tsuchiya K, Ueshima K, Hiraoka A, Ikeda M, Ogasawara S, Yamashita T, Minami T and Yamakado K: Liver Cancer Study Group of Japan: JSH Consensus-Based Clinical Practice Guidelines for the Management of Hepatocellular Carcinoma: 2014 Update by the Liver Cancer Study Group of Japan. Liver Cancer 3: 458-468, 2014.

8 Makuuchi M, Kosuge T, Takayama T, Yamazaki S, Kakazu T, Miyagawa S and Kawasaki S: Surgery for small liver cancers. Semin Surg Oncol 9: 298-304, 1993.

9 Strasberg AM and Phillips C: Use and dissemination of the Brisbane 2000 nomenclature of liver anatomy and resections. Ann Surg 257: 377-382, 2013.

10 Hatanaka K, Kudo M, Fukunaga T, Ueshima K, Chung H, Minami Y, Sakaguchi Y, Hagiwara S, Orino A and Osaki Y: Clinical characteristics of NonB NonC-HCC: Comparison with HBV and HCV related HCC. Intervirology 50: 24-31, 2007.
11 Shiraishi O, Nakai T and Kawabe T: The importance of HBVDNA in liver tissue in non $\mathrm{B}$ non $\mathrm{C}$ type hepatocellular carcinoma: analysis obtained from in situ hybridization. Med $\mathrm{J}$ Kinki Univ 28: 309, 2003.

12 Kondo K, Chijiiwa K, Funagayama M, Kai M, Otani K and Ohuchida J: Differences in long-term outcome and prognostic factors according to viral status in patients with hepatocellular carcinoma treated by surgery. J Gastrointestinal Surg 12: 468476, 2008.

13 Reddy SK, Steel JL, Chen HW, Demateo DJ, Cardinal J, Behari J, Humar A, Marsh JW, Geller DA and Tsung A: Outcomes of curative treatment for hepatocellular carcinoma in nonalcoholic steatohepatitis versus hepatitis $\mathrm{C}$ and alcoholic liver disease. Hepatology 55: 1809-1819, 2012.

14 Kaneda K, Kubo S, Tanaka H, Takemura S, Ohba K, Uenishi T, Kodai S, Shinkawa H, Urata Y, Sakae M, Yamamoto T and Suehiro S: Features and outcome after liver resection for non-B non-C hepatocellular carcinoma. Hepatogastroenterology 59: 1889-1892, 2012.

15 Wakai T, Shirai Y, Sakata J, Korita PV, Ajioka Y and Hatakeyama K: Surgical outcomes for hepatocellular carcinoma in nonalcoholic fatty liver disease. J Gastrointest Surg 15: 1450$1458,2011$.

16 Akahoshi H, Taura N, Ichikawa T, Miyaaki H, Akiyama M, Miuma S, Ozawa E, Takeshita S, Muraoka T, Matsuzaki T, Ohtani M, Isomoto H, Matsumoto T, Takeshima F and Nakao K: Differences in prognosis factors according to viral status in patients with hepatocellular carcinoma. Oncol Rep 23: 13171323, 2010.

17 Kaibori M, Ishizaki M, Matsui $\mathrm{K}$ and Kwon $\mathrm{AH}$ : Clinicopathologic characteristics of patients with non-B non-C hepatitis virus hepatocellular carcinoma after hepatectomy. Am J Surg 204: 300-307, 2012.

18 Shinkawa H, Uenishi T, Takemura S, Ohba K, Ogawa M, Ichikawa T, Kodai S, Yamamoto T, Tanaka H and Kubo S: Risk factors for postoperative recurrence of non-B non-C hepatocellular carcinoma. J Hepatobiliary Pancreat Sci 17: 291295, 2010.

19 Babali A, Cakal E, Purnak T, Biyikoglu I, Cakal B, Yuksel O and Koklu S: Serum alpha-fetoprotein levels in liver steatosis. Hepatol Int 3: 551-555, 2009.

20 Witjes CD, Polak WG, Verhoef C, Eskens FA, Dwarkasing RS, Verheij J, de Man RA and Ijzermans JN: Increased alphafetoprotein serum level is predictive for survival and recurrence of hepatocellular carcinoma in non-cirrhotic livers. Dig Surg 29(6): 522-528, 2012.

21 Abe H, Yoshizawa K, Kitahara T, Aizawa R, Matsuoka M and Aizawa Y: Etiology of non-B non-C hepatocellular carcinoma in the eastern district of Tokyo. J Gastroenterol 43: 967-974, 2008.

22 Kim SK, Marusawa H, Eso Y, Nishikawa H, Ueda Y, Kita R, Kimura T, Chiba T, Osaki Y and Kudo M: Clinical characteristics of non-B non-C hepatocellular carcinoma: A single-center retrospective study. Digestion 84(Suppl 1): 43-49, 2011.

Received March 23, 2017

Revised April 13, 2017

Accepted April 15, 2017 